\title{
Impact of Self-Perceived Dental Esthetic on Psycho-Social Well-Being and Dental Self Confidence: A Cross-Sectional Study Among Female Students in Riyadh City
}

\author{
Eman I AlSagob' \\ Fatima Alkeait ${ }^{\prime}$ \\ Lama Alhaimy' \\ Melha Alqahtani' \\ Mamata Hebbal' \\ Afnan A Ben Gassem (iD) \\ 'Preventive Dental Sciences Department, \\ College of Dentistry, Princess Nourah \\ Bint Abdulrahman University, Riyadh, \\ Saudi Arabia; ${ }^{2}$ Department of Pediatric \\ Dentistry and Orthodontics, College of \\ Dentistry, Taibah University, AlMadinah \\ AlMunawwarah, 42353, Saudi Arabia
}

Purpose: To assess the self-perceived psychological impact of dental aesthetics among female university students and its relationship to various sociodemographic factors.

Patients and Methods: A cross-sectional study was conducted on a sample of 2400 female students from various departments of selected private and public universities in Riyadh City. Participants completed an Arabic translated version of the Psychosocial Impact of Dental Aesthetic Questionnaire (PIDAQ) and a short demographic sheet. Descriptive statistics was used to describe the sample's sociodemographic characteristics as well as the mean PIDAQ scores. Bivariate analysis (ANOVA) and linear regression were used to investigate the impact of the sociodemographic factors on the mean PIDAQ scores.

Results: The pilot test revealed the instruments' conceptual equivalence, semantic equivalence and ease of comprehension. Cronbach's alpha was 0.81 , indicating good internal consistency. The total sample was 1845 with a mean age of 20.74 years. The total mean score for the (PIDAQ) was 58.10 ( $\mathrm{SD}=11.41)$. Significant differences were detected between different university affiliation in the dental self-consciousness $(<0.0001)$, social $(<0.0001)$ and psychological impacts $(0.0256)$ and the total PIDAQ scores $(0.0024)$. Significant differences were also detected between different disciplines in the dental aesthetics (0.0110) and social (0.0195) domains as well as the total PIDAQ scores (0.0144). College level was also a significant factor where middle students were significantly impacted socially (0.0026) compared to junior level students. As for the impact of income, those with the highest income displayed greater social impact (0.0039), psychological impact (0.0046) and impact on aesthetic attitude (0.0037) when compared to students with lower income levels.

Conclusion: Dental aesthetics was found to affect the psychological well-being of the subjects. University affiliation, faculty affiliation, college level, and level of income were all factors that significantly affected self-perceived aesthetics and psychosocial well-being.

Keywords: malocclusion, esthetic, perception, oral health-related quality of life, young adult, adaptation and validation

\section{Introduction}

The human face is often the feature that people observe first. As such, it plays a fundamental role in the development of an individual's self-esteem and selfimage, as positive social interactions have been shown to result in better interpersonal relationships and more self-confidence. ${ }^{1}$ The smile is considered a dynamic
Correspondence: Afnan A Ben Gassem Department of Pediatric Dentistry and Orthodontics, College of Dentistry, Taibah University, P.O Box 4I3II AlMadinah AIMunawwarah, 42353, Saudi Arabia

Tel +966500455493

Email a_bengassem@hotmail.com 
feature of facial and overall attractiveness and dental aesthetics is considered important for self-esteem. ${ }^{2}$

Dental aesthetic perceptions are found to be a prime factor in the development of a personality. ${ }^{3}$ As malocclusion, particularly that present in the anterior region, is often conspicuous, it may elicit unpleasant social reactions and a poor self-concept. ${ }^{4}$ In fact, malocclusion has been described as a physical handicap since it limits a person's social stereotype and opportunities. ${ }^{5}$ Being part of a social network, there is an inherent need for one to feel accepted. Social and appearance norms set by friends and peers may impact on individuals significantly. ${ }^{6}$ In young adults, even slight deviation from the community norms results in lack of self-esteem related to appearance and considering others "superior" to themselves. This results in a negative impact on their quality of life. ${ }^{3}$ To build a strong professional profile, self-confidence plays an important role in a person's life. ${ }^{7}$

Literature suggests that there is a strong association between self-perceived need regarding dental aesthetics and psychosocial wellbeing which in turn serves as an integral part of the general health of an individual and it should not be compromised because of bad dental aesthetics. Compromised aesthetics is a predictor of worst oral health quality of life. ${ }^{3,8}$ Hence, there has been increasing interest in the incorporation of psychometric instruments that measure oral health-related quality of life (OHRQoL). The Psychosocial Impact of Dental Aesthetics Questionnaire (PIDAQ) was created as an OHRQoL psychometric tool to assess the apparent effects that dental aesthetic concerns of young adult orthodontic patients have on their self-esteem. ${ }^{9}$ It is comprised of four subscales including Dental Self-Confidence (DSC), Social Impact (SI), Psychological Impact (PI) and Aesthetic Concern (AC). Independent of their cultural background, international studies have shown that the questionnaire has a good test quality in adults. ${ }^{4}$ They support the construct validity of the PIDAQ, considering relations to self-perceived dental aesthetics and oral health and factorial structure. Studies have shown that there is usually a discrepancy between the individuals self-perceived dental aesthetic and the actual or objective need for treatment highlighting the importance of understanding how different segments of society perceive their dental aesthetics and how it effects there psychosocial well-being. As there are so many factors that influence a smile, the impact of self-perceived aesthetics needs more exploration.
Globally, much research work has been done on dental aesthetics and psychosocial impact and factors like age, gender and educational level were found to contribute in people`s satisfaction towards dental aesthetics. ${ }^{10}$ Female adolescent patients may experience worse psycho-social impacts compared with males. ${ }^{11}$ Contemporary media and the prevailing "beauty culture" proliferate perceptions of beauty norms. Significant importance is attached to appearance and the media continues to objectify females through upholding stereotypes as to the traits that are associated with attractiveness and success. ${ }^{12}$ A study conducted in a Malaysian population reported that females were more dissatisfied than males about their dental status. ${ }^{13}$ Although men showed higher level of perfectionism than women, however, women present with greater psychosocial impact than men. ${ }^{7}$ During their adolescent years, people start to refine their self-worth, self-image, and social identity and struggle to achieve objective evaluations of their own appearance and teenagers start to develop an increasing concern for their physical appearance. ${ }^{14}$ This represents one explanation for why people's awareness of their dental aesthetic increases as they age. ${ }^{1}$ However, the existing research that has been performed in this field had yielded inconsistent findings. ${ }^{4}$ There is a likelihood that people's perceptions of their appearance evolve over time. As such, the perceptions of young females should be assessed.

Other studies have reported that dental students showed higher knowledge of aesthetics compared to their counterparts from other universities. Thus, it is concluded that awareness is a major factor which affects the judgment and perception of the observer. ${ }^{15}$ In addition, studies have shown that socioeconomic status plays a significant role in self perceived aesthetics. ${ }^{16}$ However, to date no study has been conducted that investigates whether factors such as educational background and socioeconomic status has an effect on an individuals' dental aesthetic awareness and psychosocial well-being as rated by the PIDAQ. Therefore, the aim of the present study was to assess the self-perceived psychological impact of dental aesthetics among a sample of female university students and its' relationship to various sociodemographic factors.

\section{Patients and Methods}

This was a cross-sectional study conducted from July 2018 to February 2019 across four public and private universities within the city of Riyadh, Saudi Arabia. Ethical approval was granted by the Institutional Review Board 
(IRB) of Princess Nourah bint Abdulrahman University (PNU) (H-01-R-059). The study was conducted in accordance with the Declaration of Helsinki.

\section{Study Population}

The sample comprised eligible young adult female college students who were pursuing a variety of health and nonhealth majors. Participants were included if they were students at one of the selected colleges, between the ages of 18 and 30 years and are able to read and speak Arabic. Dental students and those with a history of/ongoing orthodontic treatment were excluded from the study as it was predicted that they would have high dental aesthetic awareness and hence their perceptions would bias the results. $^{15}$

\section{Phase I: Preparation of the Research Instrument}

The "Psychosocial Impact of Dental Aesthetics Questionnaire" (PIDAQ) developed by Klages et al was used in the study. ${ }^{9}$ The PIDAQ is a psychometric instrument consisting of 23 items divided into four domains, self-confidence (six items), social impact (eight items), psychosocial impact (six items) and aesthetic concerns (three items). It is a self-rated scale with numerical values 0 "not at all", 1 "a little", 2 "somewhat", 3 "strongly" and 4 "very strongly".

The PIDAQ was translated by two independent translators (one native-English speaker who is fluent in Arabic and one native-Arabic speaker who is fluent in English) and adapted for the cultural characteristics of the study sample in line with standard recommendations. ${ }^{17}$ A "double-blind" evaluation of the translated versions was implemented with regards to the translator and the back translator. The original and back-translated versions were compared by a committee composed of a group of dental specialists with knowledge regarding QoL assessment and fluency in the English language. This committee determined the conceptual equiveillance of the questionnaire and its' relevance to the cultural context to which the PIDAQ was being adapted. Some comments and suggestions were given by the committee so that the backtranslated items would come as close as possible to those in the original questionnaire. The content validity was also assessed by this committee. ${ }^{17}$

The Arabic PIDAQ version was then pilot tested on a convenience sample of 20 female volunteers, aged 18-25 years, recruited from Princess Nourah bint Abdulrahman University, Riyadh, Saudi Arabia. Face validity in addition to ease of comprehension were evaluated via a "think aloud" technique through which the participants were requested to explain their thoughts on the questionnaire items as they responded to each question. ${ }^{18}$ Any questions or aspects of concern were noted together with details as to how long it took to complete the questionnaire. To test the internal consistency of the questionnaire a sample of 100 female students completed the final version of the Arabic PIDAQ and Cronbach's alpha $(\alpha)$ was calculated for the scale as a whole and for each individual domain. ${ }^{19}$

\section{Phase 2: Data Collection}

2400 potential participants were recruited using multistage sampling from random colleges, departments, and classes ensuring that the sample will cover students from a range of subject areas in the medical, arts and humanities and science disciplines. The universities had varying number of courses and students enrolled. The number of students selected was proportional to the total number of students studying in each university and represented approximately $10-15 \%$ of the total students.

The selected colleges were contacted prior to the distribution of the questionnaires and consent was given to approach the students. The students were briefly introduced to the study and informed consent was obtained after which the questionnaires were distributed and collected. After completion, they were served coffee and doughnuts as incentives.

\section{Statistical Analysis}

Descriptive statistics (Means, Standard deviation, frequencies and percentages) was used to describe the sample's sociodemographic characteristics as well as the mean PIDAQ scores. To test the internal consistency of the instrument, Cronbach's alpha $(\alpha)$ was calculated for the scale as a whole and for each individual domain. Bivariate analysis (ANOVA) was used to investigate the impact of the following factors on the mean PIDAQ scores; University affiliation, field of study, level of study (junior, mid-level, senior), and family income. In addition, Tukey's test was used for intergroup comparisons and Multiple linear regression analysis was used to test the influence of the aforementioned sociodemographic variables on the PIDAQ scale and subscales. The significance level was set at $\mathrm{P}<0.05$. The Statistical Package for the Social Sciences version 14.0 for Windows (SPSS Inc, Chicago, Illinois, USA) was used for the data analysis. 


\section{Results}

\section{Phase I: Psychometric Properties of the Questionnaire}

The panel of specialists agreed on the conceptual equivalence of the English and Arabic versions of the questionnaire where it was established that the subscales of the original instrument were relevant and pertinent to the Saudi context to which it was adapted. They also assured content validity. With regards to face validity, the instrument demonstrated ease of comprehension of the items by Saudi female students between the ages of 18 and 25 years of age, suggesting that the questionnaire may be administered to these subjects in the same format as the original. Semantic equivalence was achieved after making a few grammatical changes to the questionnaire structure and transferring the meaning of the concepts contained in the original instrument to the translated version, thereby giving rise to similar responses among respondents in both cultures. The time taken to complete the questionnaire was 8-10 minutes. As for the reliability of the questionnaire, Cronbach's alpha for the scales was 0.81 thus indicating good internal consistency.

\section{Phase 2: Results of the Questionnaire}

The total number of participants who returned the questionnaires were 1857 ( $77.4 \%$ response rate) female students with a mean age of 20.7 years $(\mathrm{SD}=1.7)$. The distribution of the sample's sociodemographic characteristics including age, university affiliation, field of study, college level, and income levels are presented in Table 1.

From the total sample, $41.73 \%$ of the students were studying health sciences (Medicine, Nursing, pharmacology), $12.39 \%$ social sciences (Business management and law), $16.37 \%$ engineering (architecture, science and computer science), and $29.51 \%$ arts and humanities (translation).

Overall; the total mean score (SD) for the Psychosocial Impact of Dental Esthetic Questionnaire (PIDAQ) in the current study was $58.2(\mathrm{SD}=11.4)$ with the highest rating given to the social impact domain $(23.9, \mathrm{SD}=6.3)$ followed by the psychological $(17.1, \mathrm{SD}=5.3)$, aesthetic attitude $(8.8, \mathrm{SD}=3.4)$, and dental self-consciousness $(8.5, \mathrm{SD}=5.3)$ domains respectively (see Table 2$)$.

Table 3 shows the influence of the different sociodemographic characteristics on the results of the PIDAQ scores. When comparing age groups, the results did not reveal any significant differences in the participants'
Table I Frequency and Percentages of Sociodemographic Variables

\begin{tabular}{|l|l|l|}
\hline Variables & Subcategories & N (\%) \\
\hline Age & $18-20$ & $915(49.27)$ \\
& $21-30$ & $942(50.73)$ \\
\hline University Affiliation & GUI & $701(37.75)$ \\
& GU2 & $637(34.30)$ \\
& PUI & $132(7.11)$ \\
& PU2 & $387(20.84)$ \\
\hline Field of Study & Health & $775(41.73)$ \\
& Social Sciences & $230(12.39 \%)$ \\
& Engineering & $304(16.37)$ \\
& Arts and Humanities & $548(29.5 \mathrm{I})$ \\
\hline College Level & Junior & $811(43.67)$ \\
& Middle & $758(40.82)$ \\
& Senior & $288(15.5 \mathrm{I})$ \\
\hline Income (SR) per month & $<3000$ & $84(4.52)$ \\
& $300 \mathrm{I}-6000$ & $160(8.26)$ \\
& $600 \mathrm{I}-10,000$ & $280(15.08)$ \\
& $10,00 \mathrm{I}-15,000$ & $389(20.95)$ \\
& $>15,00 \mathrm{I}$ & $944(50.83)$ \\
\hline
\end{tabular}

Abbreviations: GUI, government university I; GU2, government university 2; PUI, private university I; PU2, private university 2.

Table 2 Mean and SD for PIDAQ Subscale and Total Scores

\begin{tabular}{|l|l|l|l|}
\hline Domain & Mean & SD & Range \\
\hline Dental self-consciousness Total score: & 8.5 & 5.3 & $0-24$ \\
Social impact Total Score: & 23.9 & 6.3 & $0-32$ \\
Psychological impact total score: & 17.1 & 5.3 & $0-24$ \\
Aesthetic attitude total score: & 8.8 & 3.4 & $0-12$ \\
PIDAQ total score & 58.2 & 11.4 & $0-92$ \\
\hline
\end{tabular}

ratings across all domains. In addition, no significant differences were detected between the students of health and non-health colleges. However, significant differences were detected with respect to university affiliation in the dental self-consciousness $(p<0.0001)$, social $(p<0.0001)$ and as well as the total scores $(\mathrm{p}=0.0024)$ with those from PU2 showing the least impact compared to the rest of the students. However, in the psychological domain, those from GU1 and GU2 displayed the least impact ( $\mathrm{p}=0.0256$ ).

Significant differences were also detected in the dental aesthetics $(\mathrm{p}=0.0110)$ and social $(\mathrm{p}=0.0195)$ domains as well as the total PIDAQ scores $(\mathrm{p}=0.0144)$ between students of different fields of study where those from the Arts and Humanities faculties had the least impact. In addition, the results revealed that middle students were significantly 


\begin{tabular}{|c|c|c|c|c|}
\hline 总 & $\begin{array}{l}\stackrel{*}{\Delta} \\
\stackrel{\text { Oे }}{0}\end{array}$ & $\frac{\frac{\text { * }}{y}}{0}$ & 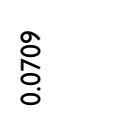 & م̃ \\
\hline 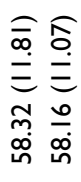 & 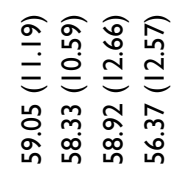 & 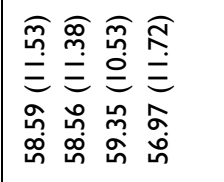 & 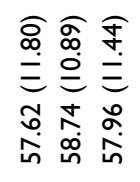 & 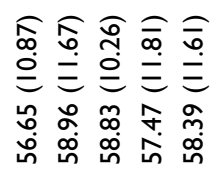 \\
\hline $\begin{array}{l}\text { ò } \\
\text { o. }\end{array}$ & $\frac{\bar{\alpha}}{\alpha}$ & 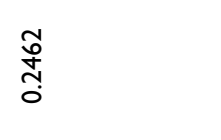 & $\begin{array}{l}* \\
\stackrel{*}{\circ} \\
\stackrel{+}{0} \\
0 \\
0\end{array}$ & $\begin{array}{l}\stackrel{*}{*} \\
\hat{O} \\
0 \\
0\end{array}$ \\
\hline 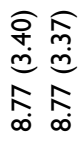 & 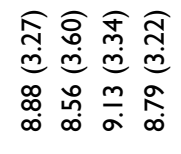 & 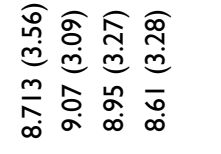 & 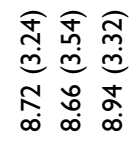 & 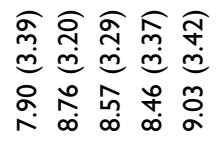 \\
\hline 商 & 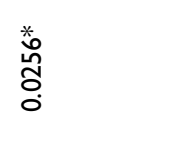 & 总 & $\frac{\hat{m}}{m}$ & 告 \\
\hline 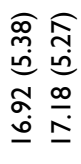 & 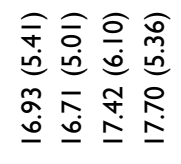 & 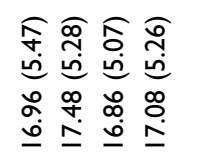 & 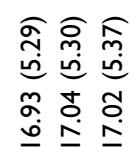 & 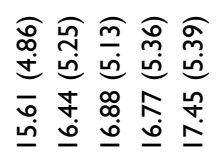 \\
\hline $\begin{array}{l}\text { 岕 } \\
\stackrel{\leftrightarrow}{0}\end{array}$ & $\begin{array}{l}\frac{\pi}{\delta} \\
\stackrel{0}{0} \\
\dot{0}\end{array}$ & $\begin{array}{l}\text { 荅 } \\
\frac{0}{0} \\
0\end{array}$ & 芯 & $\begin{array}{l}\text { مे } \\
\text { Oे } \\
\text { ơ }\end{array}$ \\
\hline 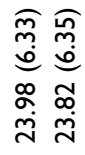 & 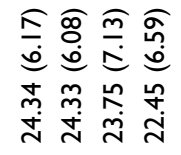 & 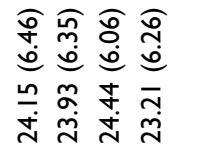 & 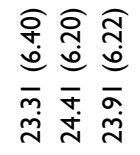 & 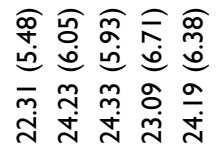 \\
\hline 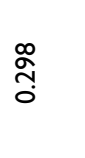 & $\begin{array}{l}\frac{*}{\delta} \\
\dot{0} \\
\dot{0} \\
v\end{array}$ & $\frac{*}{0}$ & $\frac{\infty}{0}$ & $\begin{array}{l}\frac{*}{8} \\
\dot{0} \\
\dot{0} \\
\mathrm{v}\end{array}$ \\
\hline 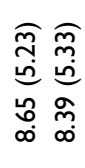 & 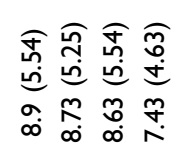 & 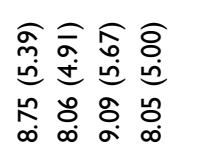 & 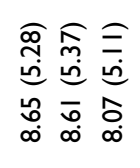 & 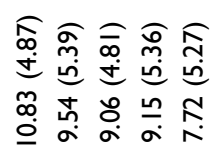 \\
\hline $\begin{array}{ll}0 & 0 \\
\text { o } & \frac{1}{N}\end{array}$ & 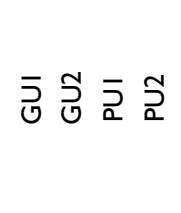 & 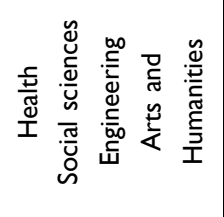 & 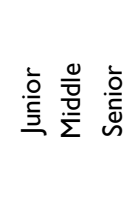 & 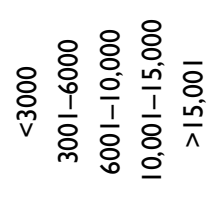 \\
\hline$\underset{<}{\stackrel{80}{\alpha}}$ & 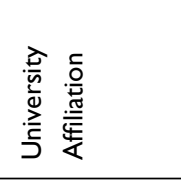 & 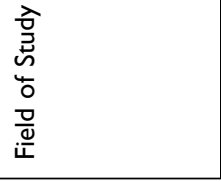 & 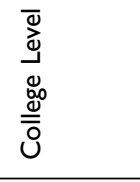 & 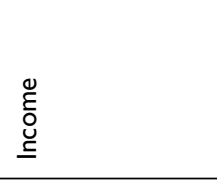 \\
\hline
\end{tabular}


impacted socially $(\mathrm{p}=0.0026)$ when compared to students at junior level.

As for the impact of income on the PIDAQ scores, the results revealed that in the dental self-consciousness domain, as income increases the impact is less $(\mathrm{p}<0.0001)$. However, those with the highest income displayed greater social impact $(\mathrm{p}=0.0039)$, psychological impact $(\mathrm{p}=0.0046)$ and impact on aesthetic attitude $(\mathrm{p}=0.0037)$ when compared to students with lower income levels.

Multivariate Linear regression results did not show any linear correlation between PIDAQ scores and any of the sociodemographic characteristics on all four domains.

\section{Discussion}

Currently; assessment of psychosocial factors of malocclusion has been considered an important part of the orthodontic examination in adults. ${ }^{9}$ The aim of the current study was to assess the psychosocial impact of dental aesthetics in undergraduate female students and its relationship to various sociodemographic factors. Previous research has found that the PIDAQ achieves a reliable test quality in adults, regardless of their cultural background. Prior studies endorse the construct validity of the PIDAQ with regards to aspects related to individual's self-perceptions of their oral health, dental aesthetics, factorial structure, and outcomes of orthodontic treatment. For the purpose of the study, guidelines set by Guillemin et al were followed to translate, cross-culturally adapt and validate the instrument to ensure the comparability of the results to international studies using the same tool. ${ }^{17}$ The back-translated version of the questionnaire was comparable to the initial form. As such, it was concluded that the Arabic and English version of the questionnaire were of suitable equivalence. The internal consistency of the Arabic translation of the PIDAQ was found to exhibit good internal reliability, as evidenced by the Cronbach's alpha coefficient of 0.81 (a reliability of 0.7 or above is deemed to be acceptable). ${ }^{19}$

The results did not show any significant association between PIDAQ scores and increasing age which may be explained by the narrow age range of the study sample reducing the probability of detecting deference's between different age groups. However, college level was found to be significantly associated with social impact scores which is in agreement with reports of previous studies that with advancing knowledge, students become more critical, aware and concerned with their dental appearance. ${ }^{20}$

In addition to college level, the results revealed that students from different fields of study also had an impact on PIDAQ scores where those from the Arts and Humanities faculties (English translation department) were least effected dentally and socially compared to their peers from the other faculties. Although other studies have reported significant differences in PIDAQ scores between students from different college departments, a clear explanation for this finding could not be determined which could be an area for further investigation Similarly, an earlier study concluded that PIDAQ scores differed between college departments and that engineering and social sciences were less impacted psychosocially than the students from other departments. ${ }^{21}$

University affiliation was found to be associated with PIDAQ scores where students from PU2 were significantly less impacted particularly in the dental and social domains than students from other universities. This may be explained by the fact that PU2 is a private university and studies have shown that students from private schools demonstrate higher self-esteem than public school students. ${ }^{22,23}$ As for income levels, although students with the highest income were least impacted on the dental self-consciousness domain, they showed greater impact on the rest of the domains compared to students with lower income levels. These results are in contradiction with the view that economic status is a key determinant of health, reaffirming a gradient in which individuals higher in the social hierarchy enjoy better health and self-esteem at each higher step of occupational grade via materialistic, behavioral and psychosocial pathways. ${ }^{24}$ The contradictory results may be due to the fact that although the students with higher income displayed positive dental self-consciousness due to easier access to dental treatment, they may be overcritical of even the smallest dental deviation causing greater impact on their psychosocial well-being.

On interpreting the results of the present study, it is important to highlight its limitations. The sample included in the study were exclusively females and hence gender differences could not be explored. Studies have shown that social and psychological impact differed between genders and it would have been interesting to find out whether this could be applied in the Saudi context which could be explored in future studies. ${ }^{11}$ Therefore, the findings of the current study should be generalized to females only with care. However, the relative gender homogeneity within the sample will have restricted the sample affording greater power to analyze other relationships. In addition, little is known about the stability of these scales over time and could be a study objective of future projects. Another 
limitation of the current study was the fact that selfperceived dental aesthetics was measured subjectively only and comparing the results to normatively assessed dental aesthetics using objective measures may have provided greater insight into the relationship of malocclusion (objectively measured) with self-perceived dental aesthetics and its effects on psychosocial well-being.

\section{Conclusion}

The Arabic version of the PIDAQ demonstrates the equivalence and cross-cultural acceptability of the tool to the original English version as well as demonstrating good internal consistency and criterion related validity.

Dental aesthetics was found to affect the psychological well-being of the subjects. University affiliation, field of study, college level, and level of income were all factors that significantly affected self-perceived aesthetics and psychosocial well-being. Due to the fact that patients' perceptions of psychosocial impact related to dental esthetics are multifactorial and are influenced by the subjective perceptions of the patient, care should be taken when planning dental services and in guiding public health practices by considering the patients' perceptions of their dental appearance as an important aspect of patient management, achieving higher levels of patient satisfaction, minimizing the risks of overtreatment and reducing costs by identifying those with a greater likelihood of benefiting from treatment.

\section{Acknowledgments}

This research was funded by the Deanship of Scientific Research at Princess Nourah Bint Abdulrahman University through the Fast-track Research Funding Program. The Authors would like to thank all the universities and students that have agreed to take part in this study.

\section{Disclosure}

The authors report no conflicts of interest in this work.

\section{References}

1. Bos A, Hoogstraten J, Prahl-Andersen B. Expectations of treatment and satisfaction with dentofacial appearance in orthodontic patients. Am J Orthod Dentofacial Orthop. 2003;123(2):127-132. doi:10.1067/ $\bmod .2003 .84$

2. Palomares NB, Celeste RK, de Oliveira BH, Miguel JAM. How does orthodontic treatment affect young adults' oral health-related quality of life? Am J Orthod Dentofacial Orthop. 2012;141(6):751-758. doi:10.1016/j.ajodo.2012.01.015
3. Nazir R, Mahmood A, Ayesha A. Assessment of psychosocial impact of dental aesthetics and self perceived orthodontic treatment need in young adults - ProQuest. Pak Oral Dent J. 2014;34(2):312.

4. Marques LS, Ramos-Jorge ML, Paiva SM, Pordeus IA. Malocclusion: esthetic impact and quality of life among Brazilian schoolchildren. Am J Orthod Dentofacial Orthop. 2006;129 (3):424-427. doi:10.1016/j.ajodo.2005.11.003

5. Rinchuse DJ, Rinchuse DJ. Orthodontics justified as a profession. Am J Orthod Dentofacial Orthop. 2002;121(1):93-96. doi:10.1067/mod. 2002.120401

6. Seehra J, Fleming PS, Newton T, DiBiase AT. Bullying in orthodontic patients and its relationship to malocclusion, self-esteem and oral health-related quality of life. J Orthod. 2011;38(4):247-256;quiz 294. doi:10.1179/14653121141641

7. Venete A, Trillo-Lumbreras E, Prado-Gascó V-J, Bellot-Arcís C, Almerich-Silla J-M, Montiel-Company J-M. Relationship between the psychosocial impact of dental aesthetics and perfectionism and self-esteem. J Clin Exp Dent. 2017;9(12):e1453-e1458. doi:10.4317/ jced.54481

8. Feu D, de Oliveira BH, de Oliveira Almeida MA, Kiyak HA, Miguel JAM. Oral health-related quality of life and orthodontic treatment seeking. Am J Orthod Dentofacial Orthop. 2010;138 (2):152-159. doi:10.1016/j.ajodo.2008.09.033

9. Klages U, Claus N, Wehrbein H, Zentner A. Development of a questionnaire for assessment of the psychosocial impact of dental aesthetics in young adults. Eur J Orthod. 2006;28(2):103-111. doi:10.1093/ejo/cji083

10. Deng X, Wang Y-J, Deng F, Liu P-L, Wu Y. Psychological well-being, dental esthetics, and psychosocial impacts in adolescent orthodontic patients: a prospective longitudinal study. Am J Orthod Dentofacial Orthop. 2018;153(1):87-96.e2. doi:10.1016/j.ajodo.20 17.05 .028

11. Christopherson EA, Briskie D, Inglehart MR. Objective, subjective, and self-assessment of preadolescent orthodontic treatment need-a function of age, gender, and ethnic/racial background? J Public Health Dent. 2009;69(1):9-17. doi:10.1111/j.1752-7325.2008.00 089.x

12. Davis SE. Objectification, sexualization, and misrepresentation: social media and the college experience. Soc Media Soc. 2018;4 (3):2056305118786727. doi:10.1177/2056305118786727

13. Tin-Oo MM, Saddki N, Hassan N. Factors influencing patient satisfaction with dental appearance and treatments they desire to improve aesthetics. BMC Oral Health. 2011;11(1):1-8. doi:10.1186/14726831-11-6

14. Josefsson E, Lindsten R, Hallberg LR-M. A qualitative study of the influence of poor dental aesthetics on the lives of young adults. Acta Odontol Scand. 2010;68(1):19-26. doi:10.3109/00016350903281740

15. Al-Batayneh OB, Owais AI, Khader YS. Oral health knowledge and practices among diverse university students with access to free dental care: a Cross-Sectional Study. Open J Stomatol. 2014;4(1):135-142. doi:10.4236/ojst.2014.43021

16. Reichmuth M, Greene KA, Orsini MG, Cisneros GJ, King GJ, Kiyak HA. Occlusal perceptions of children seeking orthodontic treatment: impact of ethnicity and socioeconomic status. Am J Orthod Dentofacial Orthop. 2005;128(5):575-582. doi:10.1016/j. ajodo.2004.09.021

17. Guillemin F, Bombardier C, Beaton D. Cross-cultural adaptation of health-related quality of life measures: literature review and proposed guidelines. J Clin Epidemiol. 1993;46(12):1417-1432. doi:10.1016/ 0895-4356(93)90142-n

18. Ericsson KA, Simon HA. Verbal reports as data. Psychol Rev. 1980;87(3):215-251. doi:10.1037/0033-295X.87.3.215

19. Kline P. An Easy Guide to Factor Analysis. Routledge; 2014.

20. Zaidi AB, Karim AB, Mohiuddin S, Rehman K. Effects of dental aesthetics on psycho-social wellbeing among students of health sciences. J Pak Med Assoc. 2020;70(6):1002-1005. 
21. Bellot-Arcís C, Montiel-Company J-M, Pinho T, Almerich-Silla J-M. Relationship between perception of malocclusion and the psychological impact of dental aesthetics in university students. J Clin Exp Dent. 2015;7(1):e18-22. doi:10.4317/jced.52157

22. Eremie M, Chikweru E. Self esteem among private and public secondary schools students in rivers state: implications for counselling. Arabian J Bus Manag Review (Kuwait Chapter). 2015;4(11):1-6. doi:10.12816/0018994
23. Taibah SM, Al-Hummayani FM. Effect of malocclusion on the self-esteem of adolescents. J Orthod Sci. 2017;6(4):123-128. doi:10.4103/jos.JOS_16_17

24. Gupta $\mathrm{E}$ The determinants of oral health related quality of life in adults; May 1, 2014. Available from: http://etheses.whiterose.ac.uk/ 6823/. Accessed February 15, 2021.

\section{Publish your work in this journal}

Patient Preference and Adherence is an international, peer-reviewed, open access journal that focusing on the growing importance of patient preference and adherence throughout the therapeutic continuum. Patient satisfaction, acceptability, quality of life, compliance, persistence and their role in developing new therapeutic modalities and compounds to optimize clinical outcomes for existing disease states are major areas of interest for the journal. This journal has been accepted for indexing on PubMed Central. The manuscript management system is completely online and includes a very quick and fair peer-review system, which is all easy to use. Visit http:// www.dovepress.com/testimonials.php to read real quotes from published authors. 